\title{
Reflexive selection of implicit indicators in the balanced scorecard of an organization
}

\author{
Dmitriy Nazarov \\ Ural State University of Economics, \\ Yekaterinburg, Russia \\ slup2005@mail.ru
}

\author{
Yuliya Kuvayeva \\ Ural State University of Economics, \\ Yekaterinburg, Russia \\ ykuvaeva1974@mail.ru
}

\author{
Anna Serebrennikova \\ Ural State University of Economics, \\ Yekaterinburg, Russia \\ serebrennikova_ai@usue.ru
}

\begin{abstract}
The paper describes a model designed to reflexively select implicit indicators of organization management using a classical approach implemented by $R$. Kaplan and $D$. Norton. According to the developed model, the entire balanced scorecard of an organization is represented in the form of a causal field structurally divided into three sub-models: "implicit indicators", "indirect indicators", and "key indicators". Such representation makes it possible not only to find implicit indicators of an organization's performance in pursuing strategic goals, but also to balance the total number of indicators on the strategy map, to assess the strength of indicators' linkage both among and within the sub-models, and to justify and coordinate their quantitative modification.
\end{abstract}

Keywords - reflexive control, balanced scorecard, organization, implicit indicators, reflexion

\section{INTRODUCTION}

Under modern conditions, a company achieves its strategic goals by building Corporate Performance Management (CPM) systems focused on developing solutions based on decomposing a strategic goal in the form of a decision tree and determining the companies' performance indicators. Models of Balanced Scorecard (BSC) of an organization are the most important subsystem for achieving the company's strategic goals within the CPM, as they allow us not only to formalize the process of their achievement, but also to monitor this process in order to make operational and tactical decisions. The BSC methodology developed by R. Kaplan and D. Norton [R.S. Kaplan, D.P. Norton, 2005] allows us to comprehensively formalize managerial decisions made to achieve the goal in two interrelated planes: to select goal achievement indicators and to implement the logic of cause-effect linkage in the goal tree. The main tool for implementing this methodology is a strategic map, the main purpose of which is to visualize the strategy for achieving an organization's strategic development goals and their monitoring. [1]
Therefore, the existence of BSC methodology itself is only a necessary condition in the context of information economy, while a sufficient condition in terms of its scalability is the availability of tools put into practice by business entities. More than 15 years of evolution of the target management concept based on balanced scorecard demonstrates that, first, it is used by almost all major consulting companies such as Accenture, Ernst \& Young, PricewaterhauseCoopers, KPMG, etc., and second, it is due to their accumulated practical experience that the concept has made it to the "packaged" product and is implemented in the form of information technology included into all basic corporate information systems (CIS). In particular, all major vendors, such as IntersoftLab, BITAM, BusinessObjects, Cognos, CristalDecisions, SAS, Hyperion, Pilotsoftware, PeopleSoft, SAP, Strategic Enterprise Management, ARISBSC, OracleBSC, etc., have an optional tool support for the BSC concept in their CIS [Galakhov, 2013].

The development and application of an organization's balanced scorecard depends entirely on decision makers and on the availability of tools for its multiple iterations during practical implementation. As a result, a behavioral paradigm has recently emerged in economics that explains the limited rationality in the management models of economic systems and their elements. This behavioral paradigm is based on the study of the behavior of decision-makers who participate in an organization's business processes and largely determine its strategy, tactics, and business activities. Perhaps the most important implication thereof is that a decision-maker has certain stereotypes in their behavior, the so-called "behavioral patterns" that fail to fit the theory of "guaranteed result", a game theory classic, and highlight its economic "poverty". In an attempt to explain this decision-maker's behavior, V.A. Lefebvre [Lefebvre V.A., Smolyan G.L., 1968, 2009] introduced the term "reflexion" into scientific use and developed a mathematical model of "conflict algebra" based on formal mathematical logic and graph theory, addressing problematic content of a phenomenon from a psychological point of view. The purpose of this paper is to implement 
reflexive selection procedure to identify implicit factors in the balanced scorecard of an organization's managerial activity. For this purpose, the following objectives were formulated: to analyze the prerequisites of an organization's reflexive control theory; to determine the role and place of implicit factors in the corporate governance under the BSC paradigm. [2]

\section{PREREQUisites FOR APPLICATION OF REFLEXIVE CONTROL THEORY IN ECONOMICS}

Studies by Nobel laureates have convincingly demonstrated that the principles of classical economic theory mainly undergo changes with time and practical experience, switching their vector to behavioral paradigm.

In 1993, the Nobel Prize was awarded to D. North [D. C. North, 1991] and R. Fogel [R. W. Fogel, 1964] for two complementary discoveries in economics. The former reinterpreted the concepts of institutions by associating them with the "rules of the game" and studied the problems of evolution of institutions themselves in terms of persistency of inefficient norms and rules. In fact, by decomposing them into two interrelated structures: formal and informal institutions. The main achievement of R. Vogel and his colleagues, the founders of "cliometrics", is of course a radical upgrade of historical and economical research methods based on the progress in econometrics, statistical and economic analysis. He was the first to draw attention to the fact that small innovations in the industry are more conducive to its evolution than major engineering discoveries. From 2001 till present, prizes have been awarded for studies that can be nominally called: "Information Economy" (George Akerlof, Michael Spence, Joseph Eugene Stiglitz); "Psychological and experimental economics" (Daniel Kahneman, Vernon Lomax Smith); "Communicative Economics" (Yisrael Robert John Aumann, Thomas Crombie Schelling); "Economic Mechanisms" (Leonid Hurwicz, Eric Maskin, Roger Bruce Myerson, Paul Krugman, Elinor Ostrom, Oliver Williamson, Peter Diamond, Dale Mortensen, Christopher Pissarides). All these studies [George J. Stigler, 1965; Kahneman D., Tversky A., 1979; Ryazanov V.T., 1998; Neumann J. von, Morgenstern O., 1970; Kanke V.A., 2007] essentially supplement the classical economic theory, filling the existing and tested provisions with new meanings and, in particular, describing from different perspectives the main objective of any economic agent, i.e. optimal behavior. The principle of uneven distribution of information ("informational economy") suggested an idea of limited rationality in the behavior of market players. Models of making decision under uncertainty aimed at optimizing the behavior of a market agent ("the psychological and experimental economics led to research") led to realization that economy is basically "human-sized" and must take this fact into account when building models of market agents' behavior. A deeper understanding of the conflict and cooperation problems under the game theory provided a concept of "focal points", i.e. points of the most probable equilibrium in a decision-maker's opinion that have not always aligned with the results of calculations in the classical game theory ("communicative economy"). The models realized in the course of theoretical and methodological studies of intrinsically different economic mechanisms only confirmed earlier studies and allowed a more qualitative explanation of the problems and paradoxes arising in practice. V.A. Lefebvre was one of the first who tried to explain the behavior of a person in the process of decision making from a psychological point of view and constructed a theory of reflexive control as a result. [3]

Initially, reflection (Lat. reflexio) was understood to mean "turning back". However, V.A. Lefebvre extended the meaning of this concept to reflection of the first type (selfreflection) and reflection of the second type. Self-reflection means a study of the cognitive act as people examine their actions, thoughts; and reflection of the second type involves making decisions on the basis of self-reflection of other people. Such interpretation of this phenomenon gave birth to a new term - "reflexive control". The term was originally used in the military; in particular, "reflexive control" was interpreted as "a process by which one enemy transmits the reasons or bases for making decisions to another." Any dodges, provocations and intrigues, disguises, plays, and deception (and generally lies in any context) could serve as such reasons [V.A. Lefebvre, 2009]. [4]

In other words, reflexive control is control, management philosophy that involves anticipating the behavior of a system as a dual "object-subject" interaction in an ever-changing environment. In other words, it is a process of "reflexive programming" of a partner or an opponent by conveying them specially prepared information to incline them to voluntarily make the predetermined decision desired by the initiator of the action. It should be noted that Yisrael Robert John Aumann in his studies already introduced the concept of "common knowledge" for the purposes of reflection of the economic system entities, which determined the value orientations of their behavior.

Matters of reflexive control in the economy were deeply analyzed and described by Ukrainian scientists under the supervision of R.N. Lepa [L.N. Lepa, M.V. Malchik, 2010]. [5]

R.N. Lepa examined the behavior of a decision maker in the context of limited time and a bipolar choice "to accept or not to accept", and argued that if a decision maker believes an issue to be less important, then the decision will be made according to a "pattern", based on intuition and knowledge, with search for similarities in the external environment, and without any thorough analysis of available data or involvement of experts, etc. That is, two types of reflections are used: type 1 (one's own experience, intuition) and type 2 (with reliance on decision-maker's external experience in similar situations).

Such management will inevitably lead to errors and, to minimize them, we need to develop models of various economic systems that, on the one hand, would take into account rational behavior of economic system by appealing to indicators already well known to science and practice; and, on the other hand, would neutralize the reflexive effects by intellectualizing decision maker's activity that minimizes the routine work done when selecting the alternatives. [6] 
Reflexive control relies on Lefebvre models which can be notionally named as "success-failure", "union-conflict", bipolar choice, and reflexive games.

In the "success-failure" model, a multi-tiered cascade of generated higher values predetermines the choice of subjects depending on the quality of relationship between them: success of one player on the metal market can either strengthen or reduce the feeling of success in the other [L. N. Lepa, M.V. Malchik, 2010].

In the "union-conflict" model, everything is predetermined by the attitude of one market player towards another. The only way to select this particular state of relationships is through a system of higher values. The model revealed an important link between the decision-makers' ethical system and the choice of attitudes towards another subject. In the first ethical system, where a combination of positive (1) and negative (0) trends is rated as negative (0), one subject generally tends to cooperate with another subject (1), while in the second ethical system he is prone to confrontation (0). Empirical analysis has demonstrated the model to explain the significant differences in normative evaluations of the choice of attitude towards alternatives in different cultures [V.A. Lefebvre, 2009].

The third model is that of bipolar choice [V.A. Lefebvre, 2009]. It emphasizes that economic behavior of a subject is not unambiguous and depends on a certain key, i.e. a criterion that would serve as a switch between positive and negative. In other words, it can deviate considerably from the result that is optimal in the paradigm. [7]

In the reflexive game theory [V.A. Lefebvre, 2009] (this is the fourth model), the anti-selfishness principle is a common value. It can be formulated as follows: every subject in a group, while pursuing their personal goals, must not cause damage to the group as a whole, i.e. actions beneficial to the subject but detrimental to the group are unacceptable, but at the same time this principle does not prohibit these actions (one versus group) if the person who commits them does not receive any benefit. The anti-selfishness principle plays about the same role in reflexive game theory that the guaranteed result principle plays in the classic game theory. Reflexive game theory allows us to predict the choices of subjects in a group if we know the graph of relations between subjects and their influence on each other.

Thus, to minimize the "broken" patterns in decision makers' behavior, it is important to apply the principles of reflexive control based on appropriate models at each "spiral turn" of an organization's business management model. For this purpose, a decision maker should perform reflexive selection of the entity's performance indicators based on data mining and its interpretation within the framework of Lefebvre's reflexive game and bipolar choice ("false" or "true") models. But such definition of the problem in the context of transition to the next wave of innovation becomes too narrow, since the implicit factors that arise in any business activity cannot be identified using traditional models of formal logic and graph theory; besides, the "true" and "false" concepts become fuzzy, as the "currency" in business relations is becoming increasingly volatile. Therefore, in our opinion, mathematical tool of the fuzzy-set theory can now be reasonably applied to the processes of reflexive selection. In fact, the uncertainty that people (decision makers, staff, etc.) always introduce into the production and management processes can only partially be accounted for by the modern mathematical apparatus.

Under the influence of human factor that is an integral part of any production technologically fair and statistically significant laws transform into regularities which, unlike strict mathematical formulas describing the laws, can demonstrate only qualitative characteristics of a process or phenomenon. As balanced scorecards of a company contain both objective, normally measured, and subjective indicators, when building strategic maps, it is mandatory to take into account the models of reflexive control of the behavior of their developers by applying to them the apparatus of fuzzy set theory.

\section{REFLEXIVE CONTROL IN THE BALANCED SCORECARD OF AN ORGANIZATION WITH REGARD TO IMPLICIT FACTORS}

Balanced scorecard conceptually belongs to the class of information systems called Business Performance Management (BPM), which is not only a new management concept, but also one of the fastest growing sectors of IT solutions. BPM includes a set of methodologies and tools that help effectively plan, measure, and analyze the business and improve its performance in an organization. [8]

BPM systems close the gap in DSS (Decision Support System) and BI (Business Intelligence) functionality allowing corporate modeling of business processes to become automatic, enable monitoring and control of an organization's key performance indicators, and are an efficient tool for (strategic and short-term) planning.

In this case, balanced scorecard of an organization essentially becomes an informational model for managing its business activity which characterizes a certain stage in the process of an organization's strategic development, so it is reasonable to say that BPM system is an informational implementation of a process approach to the company's business activity.

Business process management model for a company as an organizational and production system is, firstly, a model that presents its internal environment as a set of business processes described by a balanced scorecard decomposed in relation to a given business process; secondly, a model for translating any signal or resource received from external environment into certain value as a result of the company's activity; and, thirdly, a model implemented in the information economy and therefore making a special impact on the efficient use of information resources. [10,11]

In such model, the process of development follows a "spiral" path creating new functional module with each new turn, while the stages, levels, and types of business processes have no unambiguous breakdown into phases and can be performed in parallel, with the majority being performed pervasively, i.e. in several phases at once. Outcomes of a "spiral turn" may include process rethinking, choice of a new 
or improvement of an existing business performance model, performance interpretation and accumulation of knowledge and experience in a certain entity, as well as their synthesis and distribution.

Central link of the entire business process management model is intellectual activity and systemic thinking of decision makers and business intelligence informational systems capable of taking on a routine task of converting data into information and knowledge. This is an adequate precondition for practical application of this methodology. [9]

Development of strategic goal and then of strategic decision is influenced by many factors such as global and local trends of economic development in general and of sectoral development in particular, vision of the situation by shareholders and other stakeholders, by management of the company based on accumulated knowledge and practical experience, as well as best international practices and opinions of expert communities of various levels.

The most consistent criticism of the existing BSC model was sounded by A. O. Nedosekin et al., who noted that traditional, Norton-Kaplan type model of BSC, first, does not take into account the interests of all stakeholders who essentially form the balance of the organization's market relations in the economic system; second, has no tools for dealing with qualitative and feature factors, and third, does not take into account the relationship between projections, the disregard of which in most cases leads to management errors. The authors suggest that the BSC model be formalized in the form of a fuzzy-logical graph that will make it possible to register feedback in the system of indicators and to reveal the presence of loops, and provide an example of BSC linkages calibration based on fuzzy set theory using standard tools of five- or three-dimensional fuzzy classifier [Nedosekin A. O., 2013].

In the information economy, when informational flows become critical for the operations management system, implicit factors arise that are overlooked by the traditional BSC model but at the same time can have significant effects on the performance of an organization. Note that the nature of such factors and of their impact requires additional research, particularly in terms of their classification, impact, and performance measurement at each level. In our study, we provide only a few examples.

\section{A. Synergetic principle of the influence that implicit factors have on BSC}

Implicit factors in management arise under the influence of explicit factors already addressed in the system under inefficient management. By approximating such understanding within the reflection models, it can be argued that they arise from emerging contradictions and conflicts between the management system itself and the interests of the managed entity. Such situation leads to dynamic instability of the management system and, generally, to the emergence of temporary associations formed by organization's employees pursuing different interests and reacting differently to the achievement of strategic, tactical, and operational goals. In other words, the classic BSC theory makes it possible to construct a framework of measurable indicators of managerial performance but provides no intellectual tools for building linkages among them and, moreover, does not in any way take into account the nature of such linkages.

The ways by which such factors influence the performance of an organization have not been sufficiently studied, but implications of this influence can be demonstrated using the provisions of synergetics.

In synergetics, an ultimate state of system is known as attractor. As long as an organization, as a system, moves in the direction of attractor, its behavior can be predicted. But near the limit states, i.e. in case of extreme business performances, appears a region of unstable states, so called bifurcation points where the butterfly effect can be observed: small external influence can lead a system to diametrically opposed vectors of development - to collapse or to a new higher level of evolution. This principle can also be called a principle of resonance [Nazarov, 2012]. When applying this principle to the business processes taking place in an organization, it should be noted that balanced scorecard contains covertly implicit factors that:

1. have substantial influence on its strategic performance;

2. determine the vector of its development;

3. adjust the value orientations of its activity.

Therefore, taking into account the principle of resonance, the balanced scorecard of an organization should be modified by supplementing its model with implicit factors that will help to comprehensively address various types of uncertainty that arise in case of unforeseen situations leading to sudden losses, damage, and negative scenarios. Obviously, such system should include production risks, both strategic and operational planning risks, risks of marketing research, and financial risks.

\section{B. Modified balanced scorecard of an organization}

We will describe the BSC modified by introduction of implicit factors (see Fig. 1). Without changing the concept of R. Norton and D. Kaplan as a whole, we propose to formalize an implicit factor itself as a system of indicators that would uniquely identify it in the system of values adopted in a given organization. Each indicator of implicit factor must be measurable and, therefore, controllable, i.e. it can be changed (increased or decreased) by applying control actions. 


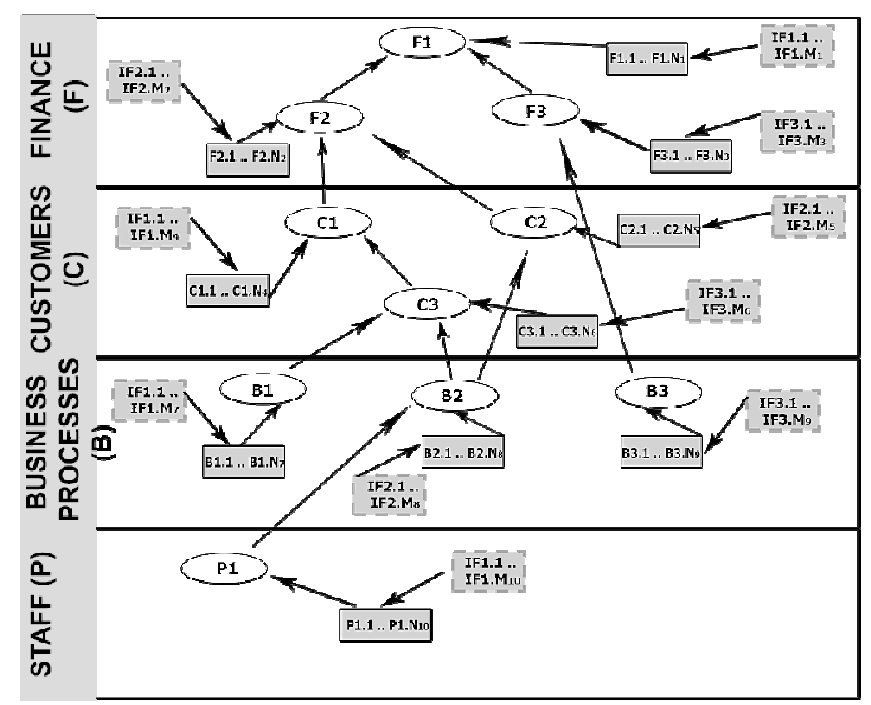

Fig. 1 - Modified strategic map of the BSC model of the organization management

In Fig. 1, the following symbols are introduced: F1 strategic targets, F1.1 to F1.N1 - indicators for monitoring the achievement of F1 goal, IF1.1 to IF1.M1 - indicators of implicit factors affecting strategic goal achievement indicators. This explication is given for the projection Finance $(\mathrm{F})$. Explication of the indicators for other projections: Clients (C), Business Processes (B), Staff (P) is unchanged

The next important conceptual element of BSC is the cause-effect relationship that shapes the logic of achieving a strategic goal. Considering the influence of implicit factors, this logic needs to be modified. It is quite clear that implicit factors may not appear in every projection, and, therefore, may influence not all the indicators but just some of them. This raises the need to propose a structural model that would allow us to identify their effects and address them through management or, in the parlance of modern socioeconomic research, to take into account the causality of linkages.

To design such model, let us hypothesize that implicit factors affect the key performance indicators of an organization indirectly. This means that all indicators selected for implementing organization's development strategy under the BSC should be decomposed into 3 groups: sub-model A will characterize implicit factors as a system of indicators; sub-model B is a set of mediated indicators, and sub-model C is a set of basic performance indicators of an organization that tend to increase its market value and shareholder value.

Therefore, to realize cause-effect (causal) linkages, we need to select indicators for these groups and build a new logic between them. In our work, we propose to implement this selection by using reflexive control models. The reason to this is that balanced scorecard is not static: its dynamics are determined in accordance with the principles of reflexive control, as well as data mining of operational and managerial activities (see Fig. 2). Elements of this model reveal that it supplements the traditional BSC model as it requires the implementation of another procedure, reflexive selection, to build sub-models A, B, C on its basis.

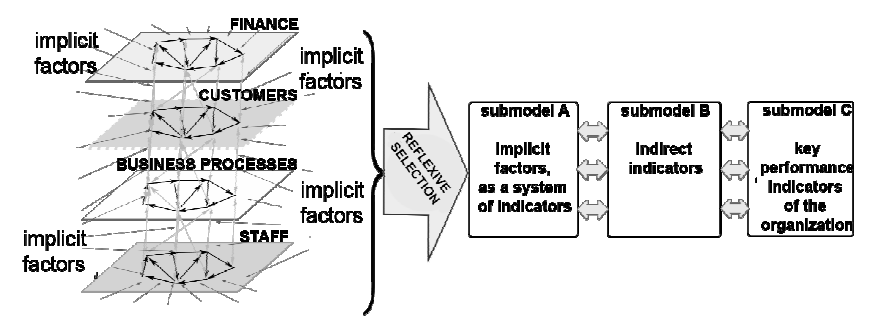

Fig. 2 - Reflexive selection model for assessing the impact of implicit factors on key performance indicators of an organization

Fig. 2 presents a framework technology of reflexive selection of business entity performance indicators, which makes it possible to assess the impact of implicit factors on the key performance indicators of an organization.

Under the reflexive selection procedure, the decision maker assigns either 0 or 1 to each sub-model and, more importantly, to each indicator, according to the logic: "excluded indicator" or "included indicator". In our work, we propose to supplement the Lefebvre model to select an optimal system of factors depending on whether it includes implicit factors based on linguistic descriptions of a decision made by decision maker.

\section{CONCLUSION}

The first feature of reflexive selection is that in a balanced scorecard, and possibly in each perspective, it identifies the indicators that characterize the implicit factors in the value system of a decision maker in a given organization.

The second feature of this model is that the indicators of implicit factors (sub-model A) influence the key performance indicators of an organization (sub-model C) not directly but through a system of measurable indicators of the sub-model B linked, on the one hand, to the main factors and to implicit ones, on the other.

The third feature of the model is that the main actors making the final choice of certain indicators (by Lefebvre's "true" - "false" formula) in reflexive selection procedure are the leader, main business processes owners acting on the basis of their experience within the corporate value system and by using data mining systems that accumulate the knowledge of an organization.

The problem of identifying and then reacting to implicit factors in organization's business and, just as importantly, to their influence on the efficiency of this business is multifaceted and requires serious scientific research, as the number of implicit factors in information economy and the degree of their influence keeps growing. Of equal importance is the problem of interpreting implicit factors in organization management to predict how this activity will develop, and to consider all possible scenarios. Solution to these problems will allow us to establish a certain relationship between order and chaos in the efficient management of an organization to 
the extent that its improvement will undoubtedly make business processes better ordered and promote its selfpreservation, and ultimately lead to a fundamental improvement of the organization's position in the relevant market segment.

\section{References}

[1] R.S. Kaplan, D.P. Norton. Balanced scorecard. Translating strategy into action. $-2^{\text {nd }}$ ed., revised and updated. Trans. from English. $-\mathrm{M}$ : ZAO Olimp-Biznes, 2005

[2] I.V. Galakhov. Designing a corporate information analysis system [Electronic source] / I.V. Galakhov [Access mode: http://www.osp.ru/text/302/182903/12.03.2013]

[3] V.A. Lefebvre. Lectures on the reflexive game theory. M: KogitoCenter, 2009

[4] North, D. C. Institutions. // Journal of Economic Perspectives - Volume 5, Number 1 - Winter 1991. P. 97

[5] Fogel R. W. Railroads and American Economic Growth: Essays in Econometric History, 1964
[6] George J. Stigler, Textual Exegesis as a Scientific Problem, Economica, New Series, Vol. 32, No. 128 (Nov., 1965), p. 448

[7] Kahneman D., Tversky A. Prospect Theory: an Analysis of Decisions under Risk // Econoraetrica. 1979. № 47.

[8] A.O. Nedosekin, M.Yu. Shkatov, Z.I. Abdulaeva. Balanced scorecard design for a mixed marine oil and gas company using fuzzy set descriptions [Text] / A.O.Nedosekin, M.Yu. Shkatov, Z.I.Abdulaeva // Audit and financial analysis. - 2013.-No. 4- P.126-134.

[9] Nazarov D. Fuzzy model for working capital speed control as an implicit factor of economy [Текст] / D. Nazarov // 19 th IEEE International Conference on Soft Computing and Measurements, SCM 2016; Saint Petersburg Electrotechnical University (SPbETU) "LETI" Saint Petersburg; Russian Federation pp. 487-488

[10] D.M. Nazarov. Methodology of fuzzy-set estimation of implicit factors in operation of an organization [Text] / D.M. Nazarov. Scientific monograph. Ministry of Education and Science of the Russian Federation, Ural. state econ. un-ty. - Yekaterinburg: [Publ. by Ural. state econ. un-ty], 2016

[11] I.S. Jacobs and C.P. Bean, "Fine particles, thin films and exchange anisotropy," in Magnetism, vol. III, G.T. Rado and H. Suhl, Eds. New York: Academic, 1963, pp. 271-350.

[12] M. Young, The Technical Writer's Handbook. Mill Valley, CA: University Science, 1989. 